\title{
Transition Zone PSA Density
}

National Cancer Institute

\section{Source}

National Cancer Institute. Transition Zone PSA Density. NCI Thesaurus. Code C20043.

The ratio of serum PSA to transition zone volume. Takes into account the size of the prostate in determining the significance of an elevated PSA level. 